\title{
Invasive paper wasps have strong cascading effects on the host plant of monarch butterflies
}

\author{
ROSE A. MC GRUD D Y, ${ }^{1}$ M A T THEW W. F. H OW S E, ${ }^{1}$ \\ J O H N A Y W O O,$^{2}$ CHRIS IE J. I. WA R D, ${ }^{3}$ \\ T O N Y B. STAUFER, ${ }^{3}$ M A R Y H A Y K-W I L L I A M S, ${ }^{3}$ \\ R I C H A R D J . T O F T ${ }^{4}$ and P H I L I P J . L E S T E R ${ }^{1}{ }^{1}{ }^{1}$ School of Biological Sciences, Victoria \\ University of Wellington, Wellington, New Zealand, ${ }^{2}$ School of Mathematics and Statistics, Victoria University of Wellington, \\ Wellington, New Zealand, ${ }^{3}$ Moths and Butterflies of New Zealand Trust (MBNZT), Nelson, New Zealand and ${ }^{4}$ Entecol Ltd., Nelson, \\ New Zealand
}

\begin{abstract}
The direct and indirect impacts that invasive predators have on communities within their invaded range are poorly understood, particularly in the early stages of invasion. Through top-down control of their prey, predators have the capacity to trigger cascading effects on lower trophic levels.

2. We found the recent arrival of the invasive paper wasp Polistes dominula Christ has been associated with substantial declines in local butterfly abundance in New Zealand. One of the butterfly species we observed to be affected is the monarch, Danaus plexippus Linnaeus with densities reduced by $66 \%$ at the study site. Field experiments were conducted to examine the strength of the predation pressure exerted by $P$. dominula on monarch caterpillars and the cascading effects on milkweed (Gomphocarpus physocarpus E. Mey.) fitness.

3. A survival study of monarch caterpillars was conducted across three habitat types (coastal, forest, and suburban). Caterpillar survival in suburban areas was lowest, with only $45 \%$ of caterpillars remaining after just $6 \mathrm{~h}$ of exposure to wasp foraging. Predation by $P$. dominula explained $85 \%$ of caterpillar deaths within the trial period.

4. The cascading effects of $P$. dominula presence were quantified through changes in the height, foliage, and reproductive output of milkweed plants. Monarch caterpillar predation by $P$. dominula was found to have a positive effect on milkweed fitness.

5. This study demonstrates a strong trophic cascade initiated by an invasive predator. These findings highlight the impacts an invasive species can have on local communities beyond their direct predatory effects.
\end{abstract}

Key words. Danaus plexippus, Gomphocarpus physocarpus, introduced species, predation, Polistes dominula, trophic cascade.

\section{Introduction}

Predation has been widely demonstrated as an important biotic process, influencing the density and distribution of prey (Terborgh et al., 2001; Worm \& Myers, 2003; Moon \& Silva, 2013). The effects of this top-down control on prey population dynamics can extend indirectly to lower trophic levels (Halaj \& Wise, 2001; Borer et al., 2006; Liere et al., 2015). Predators,

\footnotetext{
Correspondence: Rose A. McGruddy, School of Biological Sciences, Victoria University of Wellington, PO Box 600, Wellington, New Zealand., E-mail: rose.mcgruddy @ vuw.ac.nz
}

therefore, have the capacity to structure communities and alter species diversity (Shears \& Babcock, 2002; Beschta \& Ripple, 2009; Britten et al., 2014). However, invasive predators can have detrimental effects on communities, as prey species often do not share an evolutionary or ecological history with the intruder (Gurevitch \& Padilla, 2004; Salo et al., 2007). This novelty leaves prey vulnerable to exploitation by the invasive predator, which can have flow-on effects for other trophic levels (O’Dowd et al., 2003).

Hymenopteran insects are particularly successful invaders, with the ability to have substantial impacts on native biodiversity 
(Lester \& Beggs, 2019). These invasive predators and their capacity to decimate native invertebrate communities directly have been well documented (Toft \& Rees, 1998; Beggs \& Rees, 1999; Potter-Craven et al., 2018). Yet the indirect effects these predators can have on lower trophic levels within their invaded range has received less attention. Due to the invasion success and strong predatory effects of these social insects, they are likely to be important instigators of trophic cascades (Holway et al., 2002; Rosumek et al., 2009).

We examined both the direct and indirect effects of the invasive European paper wasp Polistes dominula Christ. This predatory wasp has successfully invaded several continents (Cervo et al., 2000; Liebert et al., 2006; Benade et al., 2014), including a recent invasion of New Zealand in the last decade. The presence of this invader was first realised in New Zealand in the summer of 2015, although it has been estimated that P. dominula could have arrived as early as 2011 (MPI, 2016). This wasp is a generalist predator, which preys upon a variety of Lepidopteran species (Cervo et al., 2000), including the monarch butterfly, Danaus plexippus Linnaeus (Rayor, 2004).

In this study, larvae of the monarch butterfly and their milkweed host plant (Gomphocarpus physocarpus E. Mey.) were used to test the direct and indirect effects of $P$. dominula. Native to North America, the monarch butterfly is an assisted immigrant in New Zealand, first recorded in the early 1840s (Zalucki \& Clarke, 2004). The introduction of milkweed plants, which host monarch caterpillars, was necessary for this butterfly to successfully establish and persist in New Zealand (Wise, 1980). Anecdotally, a decline has been observed in monarchs and other Lepidopteran populations in the Nelson region of New Zealand over the last decade, with residents attributing the cause to the newly invasive paper wasp $P$. dominula. There are other possible explanations for these declines; however, as $P$. dominula is not the first paper wasp to invade New Zealand. A close relative, the Asian paper wasp, Polistes chinensis Pérez, invaded in the 1970s and since then has become well established in many parts of the country (Clapperton et al., 1996). Monarch caterpillars, among other Lepidopteran larvae, are prey species of $P$. chinensis in New Zealand (Ward \& Ramón-Laca, 2013). Predation pressure exerted by $P$. dominula alone, or in addition to predation by the already established $P$. chinensis, could be instigating these butterfly declines. Discovering the driver behind these declines in Lepidopteran populations is important as there are implications for the wider invertebrate community and conservation efforts (Beggs \& Rees, 1999; Brockerhoff et al., 2010; Beggs et al., 2011).

We present the results of an annual butterfly survey, which exhibited changes in Lepidopteran populations following the arrival of $P$. dominula. We also examined the direct effects of this predatory, invasive wasp on monarch caterpillars and the indirect effects of this predator-prey interaction on the fitness of the milkweed host plant. In a field experiment, the survival rates of monarch caterpillars within suburban, coastal, and forest habitats were recorded. We hypothesised that $P$. dominula would be the primary cause of caterpillar mortality. We also predicted that through the direct predation of monarch caterpillars, paper wasps would indirectly alter plant biomass and fitness (Fig. 1). Released from herbivory, introduced milkweed, with a high reproductive rate, wind dispersal, and few other herbivores, has the potential to become so abundant that people could perceive it as a pest.

\section{Materials and methods}

\section{Annual survey of butterfly abundance}

The estimates of annual butterfly abundance were undertaken using a citizen science project. A transect walk was conducted in the residential area of Nelson $\left(41.2985^{\circ} \mathrm{S}, 173.2441^{\circ} \mathrm{E}\right)$, from 2009 to 2020 recording adult abundance of three common Lepidopteran species (D. plexippus, Pieris rapae Linnaeus, 1758, and Zizina labradus Godart). The transect line was $4.7 \mathrm{~km}$ long and the walk was conducted roughly once a week by two of the authors (C.J.I.W. and T.B.S.) over the summer from December to March. Walks were undertaken between the daylight hours of $10 \mathrm{am}$ and $4 \mathrm{pm}$ on days with calm weather. The walk encompassed a mixture of suburban streets and riverside reserves. All butterflies that were identifiable as far as the eye could see from the transect line were recorded.

\section{Experiment 1 - Predation of caterpillars by Polistes dominula}

This field study was conducted in the Nelson region of New Zealand in late summer, in February 2020, when wasp densities were high. Six sites were chosen to quantify the predation pressure of paper wasps on monarch caterpillars: two suburban, two coastal, and two forest. Both suburban sites were residential areas containing a house and garden area. Both gardens contained a mix of native and exotic shrubs, flaxes, and herbaceous plants, with mature trees along the back boundary of the properties. Coastal sites were within $100 \mathrm{~m}$ of the high tide line and lacked any permanent anthropogenic structures. These coastal sites were comprised of a mix of sedges, herbaceous plants, shrubs, and grasses. One of the coastal sites contained plastic plant protectors as part of a local conservation programme, which both Polistes spp. were observed to utilise as nesting sites. Forest sites were $50 \mathrm{~m}$ in from the forest edge, with a canopy cover of $>50 \%$ and both sites comprised a mix of exotic and regenerating native forest. The suburban sites either contained or were in close proximity to, several self-sown Gomphocarpus plants. There did not appear to be any milkweeds growing in close proximity to any coastal or forested sites.

Each study site was roughly $700 \mathrm{~m}^{2}$ in size. Wasp nest densities of both $P$. dominula and $P$. chinensis were estimated by thoroughly searching within the chosen site and recording the nests found and counting the number of wasps per nest. This estimate was then scaled to give an estimate of wasp densities per $1000 \mathrm{~m}^{2}$ for each site. Previous research has found the foraging distance of Polistes spp. to be roughly $150 \mathrm{~m}$ (Dew \& Michener, 1978), so calculations of wasp densities in the area could be an underestimate of the number of wasps within range of the experiment.

Monarch caterpillars were used for this experiment as their larval stage occurs when paper wasp densities are high. They 


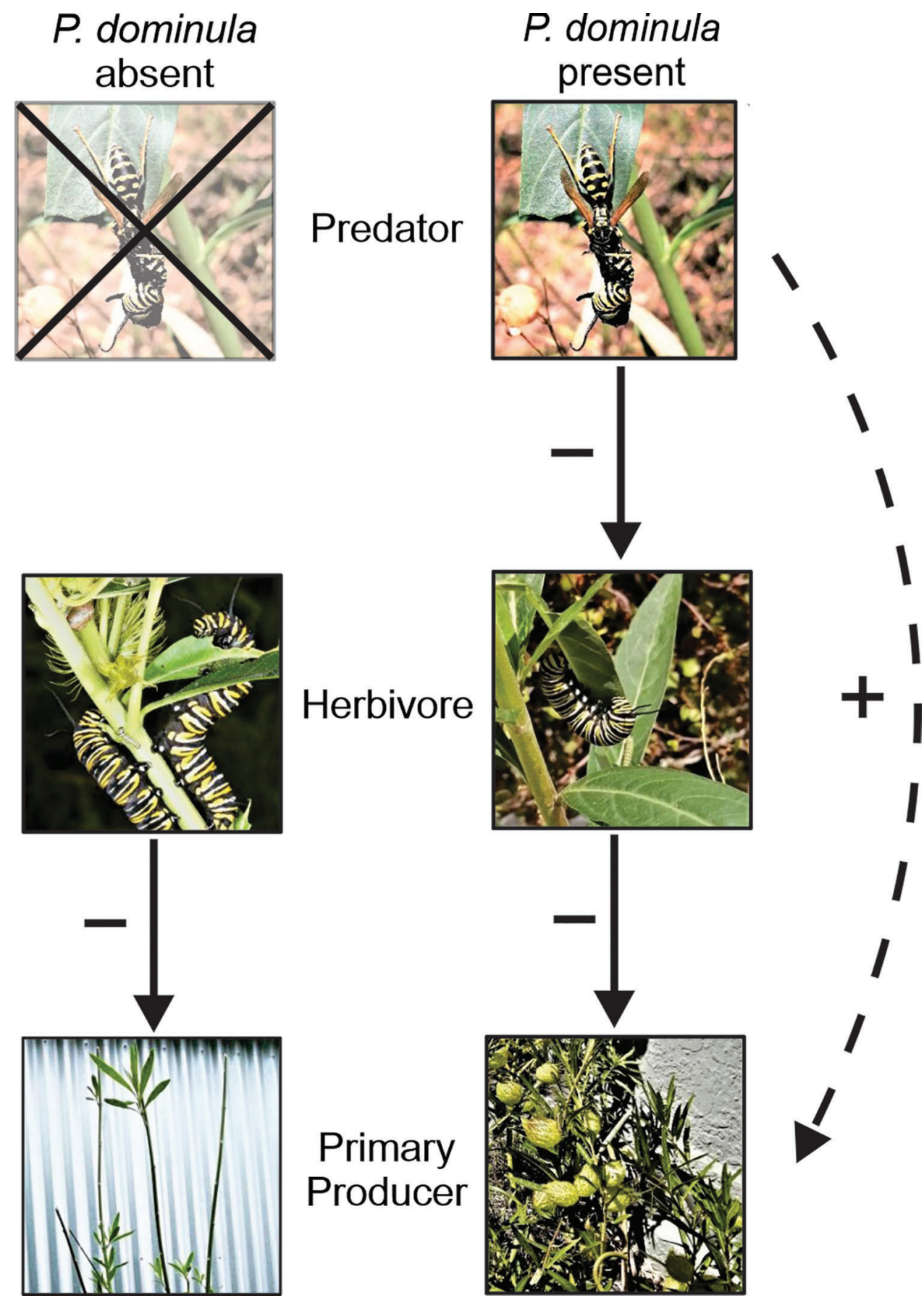

Fig. 1. Trophic interactions between the predator Polistes dominula, monarch caterpillar herbivore, and primary producer Gomphocarpus physocarpus. The wasp has negative, direct effects on caterpillars through predation. Caterpillars have negative, direct effects on the host plant through herbivory. The predicted beneficial, indirect effects of wasp predation for host plant fitness is represented by the dashed line. Photo credit: Philip Lester and Rose McGruddy. [Colour figure can be viewed at wileyonlinelibrary.com].

are also a common species in suburban habitats of New Zealand (Wise, 1980). The caterpillars used in this experiment were reared from eggs gathered in situ from milkweeds in the Nelson region and kept safe from predators within a netted enclosure. At the time of the experiments, there was a wide range of caterpillars across all instars. To discover the effect of caterpillar size on survival, the caterpillars were separated into two groups. Caterpillars from the second through to early fourth instar were classified as 'small' and late fourth instar through to fifth instar were classified as 'large'. In order to record 
caterpillar survival as accurately as possible, the experiment was carried out at two study sites per day across three days, rather than all six sites simultaneously. Two observers conducted the experiment (R.A.M. and M.W.F.H.), one at each site. To reduce the influence that variable weather conditions could have on results, experimental days were chosen when weather was predicted to be relatively sunny, with no rain, low winds, and maximum temperatures of $21^{\circ} \mathrm{C}$ or higher.

Six potted milkweed plants were chosen for each site, three of which were covered in an insect-proof cloth as a control to exclude Polistes wasps. The plants used were between 71 and $95 \mathrm{~cm}$ tall. Five small and five large caterpillars were assigned to each individual plant. Caterpillars were placed on their respective plants an hour before the experiment to give them time to settle. Pairs of plants (one exposed and one control) were then placed within the study site with a spacing between plant pairs of at least $20 \mathrm{~m}$. These milkweed plants were monitored at the sites for $6 \mathrm{~h}$ between the hours of 10:30 and 11:00 and 16:30 and 17:00 when wasps are observed to be actively foraging. Hourly counts of remaining caterpillars were recorded, as well as any additional observations of caterpillar mortality between these hourly intervals. Where possible, the cause of caterpillar mortality/absence was recorded.

The majority of caterpillars used in this experiment were too large for either Polistes spp. to remove in a single flight, so the wasp that initiated the attack would often return repeatedly to cut and remove a food bolus from its prey. If the exact moment of attack on a particular caterpillar was not observed, but a wasp was seen to be collecting a food bolus from the caterpillar, this wasp was assumed to be the cause of death. On occasion, fifth instar caterpillars were found on the ground or vegetation in close proximity to their respective milkweed plant. This behaviour was observed during both trials for all habitat types and was likely driven by the individuals' need to pupate. If discovered, the caterpillars were returned to their plant. The wasp species, size, and nest location were noted to determine how many wasps successfully predated caterpillars on a particular plant. It is possible to identify individual wasps of $P$. dominula based on features such as facial (Tibbetts \& Lindsay, 2008) and thoracic markings, wasp size, and direction of flight path. The identification of individual wasps was assessed predominantly by looking at markings on the face, as the size, shape, and number of black spots on the clypeus of $P$. dominula are highly variable (Fig. 2) (Tibbetts \& Dale, 2004). Two trials of this experiment were conducted on consecutive weeks: trial 1, 9-14 February and trial 2, 16-20 February 2020.

\section{Experiment 2 - Cascading effects of Polistes dominula predation on host plant fitness}

The cascading effects of $P$. dominula on milkweeds were tested in a field experiment from January to March 2020. This experiment was done simultaneously in both the Nelson region, where $P$. dominula is present, and the climatically similar Wairarapa region $\left(40.9449^{\circ} \mathrm{S}, 175.6690^{\circ} \mathrm{E}\right)(\mathrm{NIWA}, 2016)$, where $P$. dominula is yet to establish. Ideally, the two regions would have been in closer proximity, however, this was not possible with the current distribution of $P$. dominula. Three suburban sites were selected within each region. Five milkweed plants were placed within each site, two of which were controls covered by insect-exclusion nets to prevent $D$. plexippus butterflies from laying their eggs and to exclude wandering caterpillars. This gave a total of 15 plants in $P$. dominula occupied areas and 15 in areas where $P$. dominula was absent. The milkweeds were in free-standing pots, placed in garden areas where they would receive full sun. Groundcover in these gardens varied both between and within sites, ranging from grass and soil to bark or gravel. Height of the surrounding vegetation varied, with some milkweeds standing alone, metres from other vegetation, while others were within proximity of mature trees upwards of $4 \mathrm{~m}$ tall. Plants were watered every two to three days as needed.

In both regions the exposed milkweed plants were available for the natural colonisation of D. plexippus. Resulting caterpillars can cause substantial damage to their host plant through the consumption of leaves, stems, and flowers. The cascading effects of $P$. dominula on the host plant were, therefore, measured through changes in plant growth (height and leaf number) and reproductive output (number of flowers per plant) at the end of eight weeks. A measure of seed pods would have given a better estimate of reproductive output, but constraints of the experimental design prevented this, as the insect-exclusion nets used for the control plants excluded both caterpillars and pollinators.

To control for as much variation in plant changes as possible between the two regions, all 30 plants were transplanted into $20 \mathrm{~cm}$ pots containing the same brand of potting mix. Prior to the experiment, any invertebrate inhabitants that could confound results, such as aphids or monarch eggs, were removed from all plants. Plant height, leaf number, and flowers were counted for each individual plant before the experiment. The initial height of plants from the soil line within each pot ranged between 75 and $102 \mathrm{~cm}$. The initial number of leaves per plant ranged from 86 to 257 . The flowers of $G$. physocarpus are primarily white and grouped in drooping umbels of approximately eight flowers. No plants were flowering prior to the experiment.

\section{Statistical analysis}

Statistical analyses were conducted in R 3.6.0 (R Development Core Team, 2020). Data from the annual butterfly survey were grouped according to the year the summer season began. As butterfly numbers tend to fluctuate based on each species life cycle, butterfly counts from each walk were averaged for each month of December, January, February, and March for comparison between species. In the summer beginning in 2014, only one weekly survey was conducted for the months of February and March, which was presented as the average for that month. The summer of 2015 is estimated to be the time when $P$. dominula was introduced and became abundant in the region. For a statistical comparison of butterfly abundance before and after the establishment of $P$. dominula, the dataset was split. Butterfly counts from 2009 to 2014 were placed into one group and the counts from 2015 to 2019 were placed in 


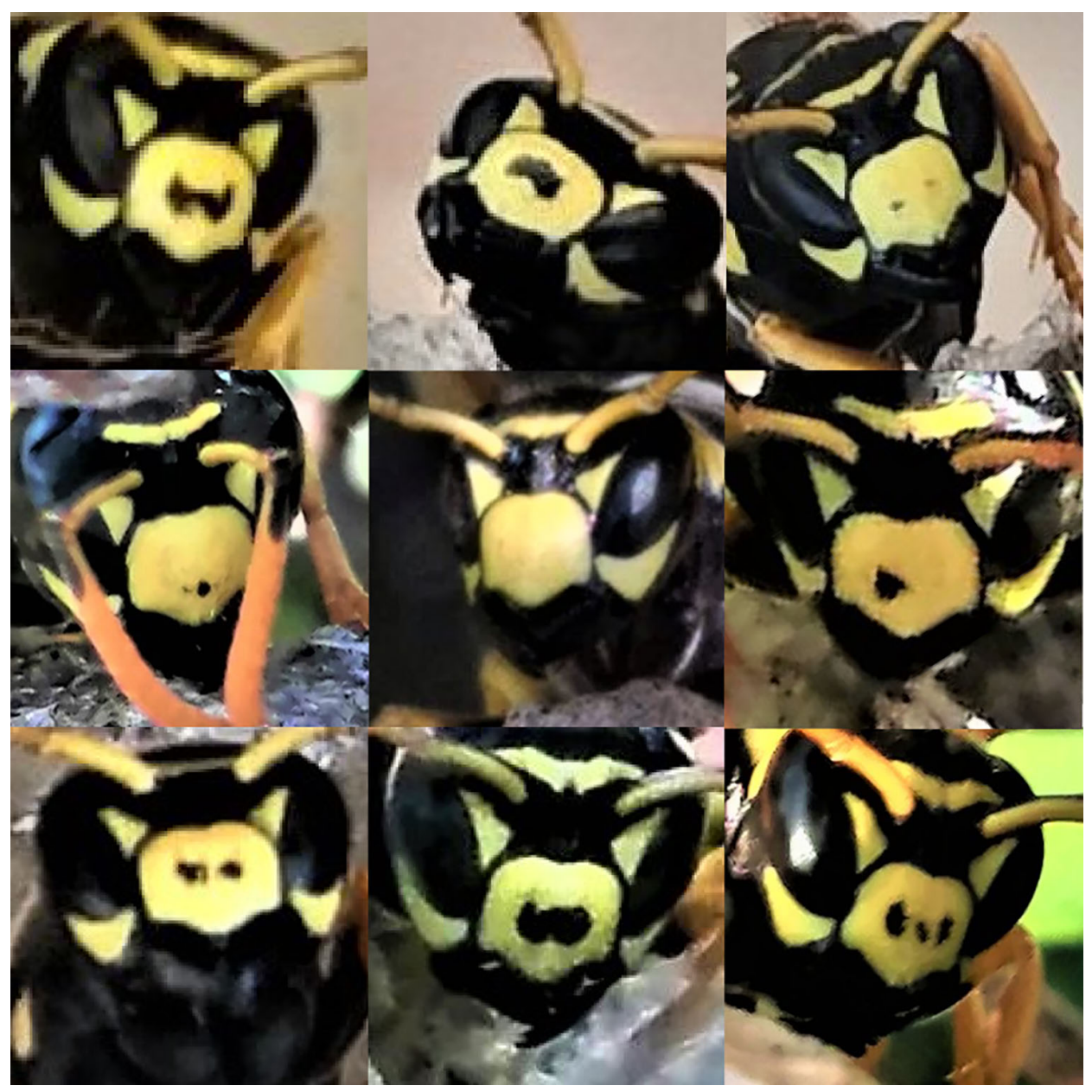

Fig. 2. Photos exhibiting the high variation in black spot patterning on the clypeus of Polistes dominula, which can be used to identify individual wasps. Photo credit: Rose McGruddy. [Colour figure can be viewed at wileyonlinelibrary.com].

another. To ensure approximate normality of the data, counts for D. plexippus, P. rapae, and Z. labradus were square-root transformed before they were analysed using ANOvA.

The results of the first experiment investigating the effects of $P$. dominula predation on monarch caterpillars did not differ significantly between trial 1 and trial 2, so the datasets were combined for analysis. Monarch caterpillar survival was investigated using the 'survival' and 'survminer' packages to generate Kaplan-Meier plots to visualise survival curves, with differences between these curves analysed using pairwise log-rank tests (Jager et al., 2008). Not all instances of caterpillar absence could be attributed to death, as there were a small number of cases where caterpillars were simply absent from the plant, with no evidence of predation (caterpillar remains, haemolymph on leaves, etc.). The majority of these unexplained absences involved caterpillars that were in their fifth instar stage that had likely left the plants in search of a suitable place to pupate. In the absence of contrary evidence, however, these absences were still coded as a death event in the survival analyses. Logistic regression was used to assess the relationship between estimated densities of Polistes spp. and caterpillar survival. The indirect effects of $P$. dominula on changes in host plant height, leaf number, and reproductive output were analysed using a one-way ANOVA, with data tested to ensure normality. Pairwise comparisons between groups were conducted using Tukey's post hoc analysis.

\section{Results}

\section{Annual survey of butterfly abundance}

There was a significant decline in butterfly abundance across all three butterfly species (D. plexippus, P. rapae, and $Z$. labradus) from the summer beginning in 2015 (Fig. 3a-c). The grouped average butterfly abundance for the summers of 2015-2019 was significantly lower than the grouped average butterfly abundance for the summers of 2009-2014. There was an overall decrease of $66 \%$ for $D$. plexippus $\left(F_{1,152}=79.89\right.$, $P<0.001)$, 54\% decrease for $P$. rapae $\left(F_{1,152}=61.95\right.$, $P<0.001)$, and $87 \%$ decrease for Z labradus $\left(F_{1,152}=26.85\right.$, $P<0.001)$. A small spike in abundance can be observed in February and March of the 2019 summer for both D. plexippus 

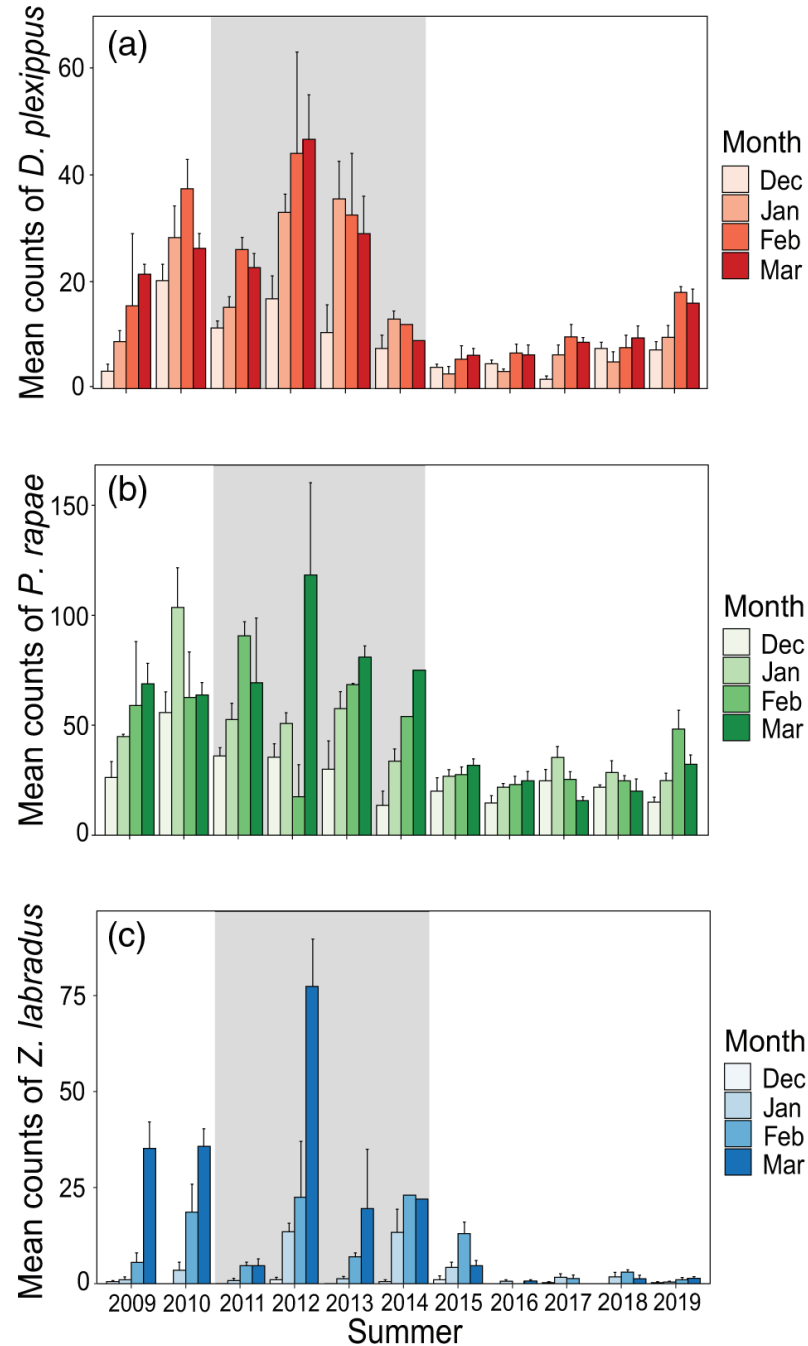

Fig. 3. Data from an annual survey in Nelson showing mean (+1 SE) butterfly abundance for three local species: (a) Danaus plexippus, (b) Pieris rapae, and (c) Zizina labradus. Butterfly abundance is presented from the months of December through to March over 11 summers. The area highlighted in grey from 2011 to 2014 is the likely timeframe of Polistes dominula invasion in Nelson, New Zealand. [Colour figure can be viewed at wileyonlinelibrary.com].

and $P$. rapae, which may be indicative of early stages of population recovery for these two species. To consider climate as an explanation for changes in abundance, further analyses were conducted investigating the possible effects of rainfall and air temperature on butterfly numbers (Table S1 \& S2, Fig. S1 \& S2). These climate variables did not differ significantly in the periods before and after $P$. dominula introduction $(P \geq 0.199)$ so they are unlikely to have affected the patterns of observed butterfly abundance.

\section{Predation of caterpillars by Polistes dominula}

Predation by P. dominula was the reason for $85 \%$ of monarch caterpillar deaths on milkweed plants across both trials (Fig. 4).

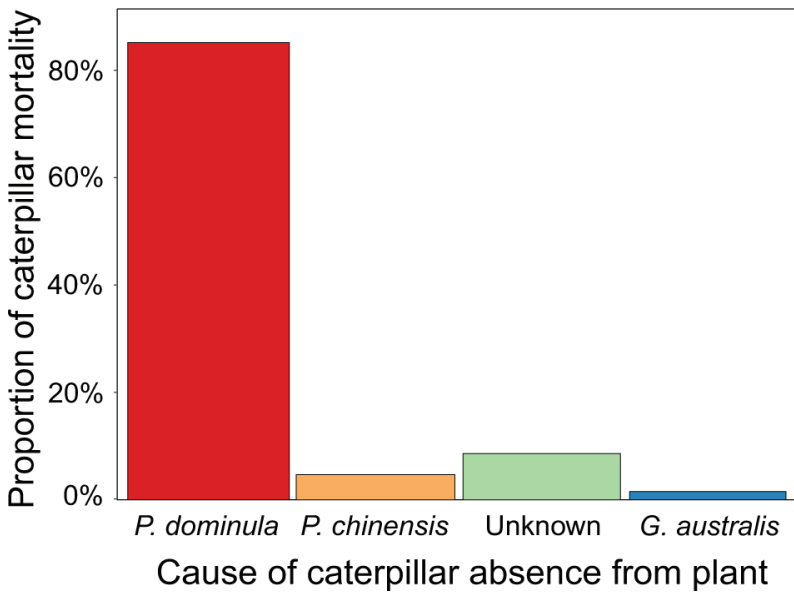

Fig. 4. A summary of the cause of death/absence of monarch caterpillars for three habitat types combined (suburban, coastal, and forest) over a 6-h time period. The total mortality of caterpillars shown is for two trials. [Colour figure can be viewed at wileyonlinelibrary.com].

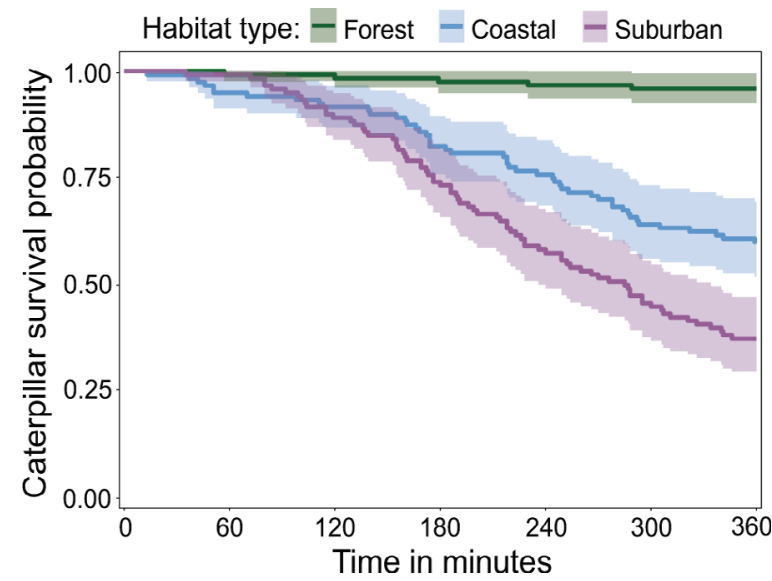

Fig. 5. Kaplan-Meier survival estimates $( \pm 95 \% \mathrm{CI})$ on the survival of monarch caterpillars based on habitat type (suburban, coastal, or forest) over a 6-h time period. Survival curves are the combined results of two trials $(n=120$ for each habitat type). Pairwise log-rank tests were used to compare survival of caterpillars in each type of habitat. [Colour figure can be viewed at wileyonlinelibrary.com].

Predation by P. chinensis explained just $5 \%$ of caterpillar deaths, while the cause of $9 \%$ of caterpillar absences was unknown. During trial 1 at a suburban site, a weka (Gallirallus australis), a bird native to New Zealand, pecked and killed two monarch caterpillars, but did not consume them, accounting for the final $1 \%$. Caterpillar survival rates differed significantly for all three habitat types (Pairwise log-rank test, $P<0.05$, Fig. 5). Overall, caterpillar survival in suburban areas was the lowest, with only $45 \%$ remaining after just $6 \mathrm{~h}$ of exposure. Survival in coastal areas was higher than suburban, with $64 \%$ of caterpillars surviving the trial. Forest sites had the highest survival rates, with $96 \%$ of caterpillars found to still be on the plant after $6 \mathrm{~h}$. Of the small proportion of caterpillars that were unaccounted for in the forest sites, predation was not observed to be the cause of absence. 


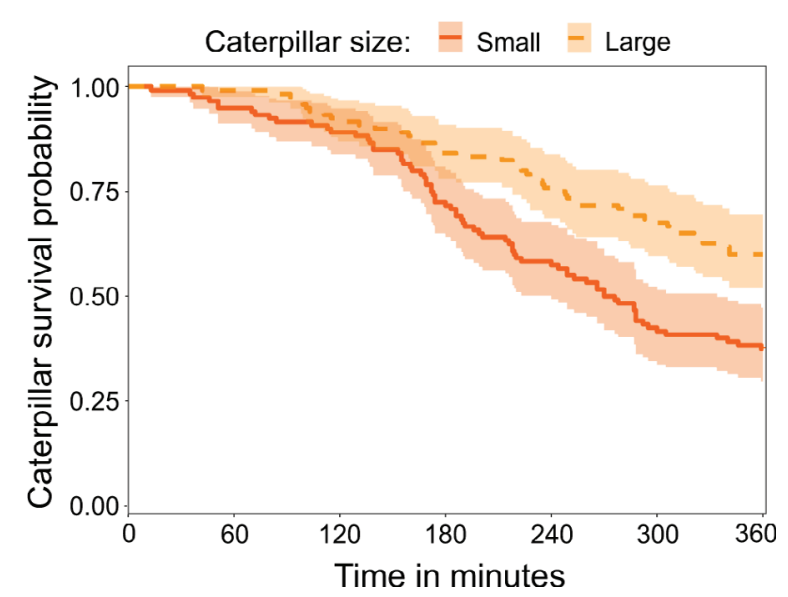

Fig. 6. Kaplan-Meier survival estimates $( \pm 95 \%$ CI $)$ of monarch caterpillars in areas occupied by the wasp Polistes dominula, based on caterpillar size over a 6-h time period. Survival curves are the combined results of two trials $(n=240)$. A log-rank test was used to compare survival of small caterpillars (second - early fourth instar) with that of large caterpillars (late fourth - fifth instar). [Colour figure can be viewed at wileyonlinelibrary.com].

The probability of caterpillar mortality increased significantly as densities of $P$. dominula increased (estimate $=0.011$, $\mathrm{SE}=0.002, P<0.001)$. Suburban sites had the highest $P$. dominula densities, with an average of $104 \pm 2.6$ wasps per $1000 \mathrm{~m}^{2}$ (Table S3). Densities of $P$. dominula in coastal sites were lower, with an estimate of $65 \pm 5.5$ wasps per $1000 \mathrm{~m}^{2}$. Estimated densities of $P$. chinensis were not significantly associated with the probability of caterpillar mortality (estimate $=-0.02$, $\mathrm{SE}=0.012, P=0.119)$. The average densities of $P$. chinensis in the suburban and coastal sites were $3 \pm 0.1$ wasps per $1000 \mathrm{~m}^{2}$ and $22 \pm 0.5$ wasps per $1000 \mathrm{~m}^{2}$, respectively. No nests of either $P$. dominula or $P$. chinensis were found within the forest sites, and therefore, the densities of paper wasps in these areas were recorded as zero.

Small caterpillars had a lower chance of survival than large caterpillars at sites occupied by $P$. dominula, as small caterpillars constituted $61 \%$ of all deaths (log-rank test, $\chi^{2}=13.5$; $P<0.001$, Fig. 6). Large caterpillars were frequently observed to rear and thrash their bodies when attacked by $P$. dominula, sometimes deterring the wasp sufficiently for it to search elsewhere. Small caterpillars were not as successful in deterring wasps when exhibiting similar behaviour.

Of plants where $P$. dominula discovered caterpillars, $42 \%$ were discovered by only one wasp. That individual would continue to return to the plant repeatedly to search for more caterpillars throughout the day. The maximum number of wasps to discover caterpillars on a single plant within the 6-h timeframe was five. In instances where multiple wasps found a plant, they often left in different directions, indicating they were from different nests.

\section{Cascading effects of Polistes dominula predation on host plant fitness}

In the absence of the predatory $P$. dominula, monarch caterpillars significantly impacted milkweed growth (Fig. 7a), with the height of exposed plants increasing by only $3 \%$ on average. This change in height differed significantly to the observed height increase of $42 \%$ for the associated control plants, which excluded caterpillars completely $(P<0.001$, one-way AnOva, Tukey's post hoc). In the presence of $P$. dominula, predation of monarch caterpillars was so effective at reducing plant damage that changes in plant height did not differ significantly between the increase of $35 \%$ for the exposed treatment and 38\% for the associated control ( $P=0.944$, one-way ANOva, Tukey's post hoc). Changes in height for exposed plants in $P$. dominula occupied areas also did not differ significantly to the changes in height observed for control plants in areas without this wasp $(P=0.786$, one-way ANOva, Tukey's post hoc).

Monarch caterpillars substantially reduced the number of leaves on exposed milkweeds in areas where $P$. dominula were absent (Fig. 7b), with an average leaf decrease of 63\%, which differed significantly from the average leaf increase of $57 \%$ for the associated control plants $(P<0.001$, one-way ANOVA, Tukey's post hoc). Again, the strong, indirect effect $P$. dominula had on reducing plant damage caused by monarch caterpillars meant changes in leaf number did not differ significantly between the $96 \%$ increase for the exposed treatment and $96 \%$ increase for the associated control $(P=0.993$, one-way ANOVA, Tukey's post hoc). There was also no significant difference in leaf changes between exposed plants in areas with this wasp and control plants in areas without $P$. dominula $(P=0.996$, one-way ANOva, Tukey's post hoc). It should be noted that minor leaf damage was observed on leaves in the presence of $P$. dominula, indicating that caterpillars were hatching and consuming plant material. However, these caterpillars appeared to be removed before they could cause extensive damage to plant growth.

Exposed milkweeds in areas without $P$. dominula produced an average of $29.8 \pm 19.9$ flowers, with control plants in the area producing an average of $259 \pm 41.5$ flowers. The difference in flower number between the two treatments was significant $(P<0.001$, one-way Anova, Tukey's post hoc, Fig. 7c). This result shows that caterpillar herbivory likely had a strong enough effect to negatively impact plant reproduction. The number of flowers per plant did not differ significantly between exposed milkweeds in areas where $P$. dominula was present relative to the associated control $(P=0.999$, one-way ANOVA, Tukey's post hoc). The average number of flowers on plants for the exposed and control treatments in the presence of P. dominula was $99.6 \pm 30.7$ and $105 \pm 43$, respectively. This similarity between exposed and control treatments suggest $P$. dominula can remove caterpillars effectively enough to prevent herbivory from having significant, detrimental effects on plant reproduction. There were roughly three times the average number of flowers on exposed plants in $P$. dominula occupied areas $(99.6 \pm 30.7)$ compared to exposed plants in areas where $P$. dominula were absent $(29.8 \pm 19.9)$, however, the difference in flowers produced was not significant $(P=0.569$, one-way ANOva, Tukey's post hoc). There was a significantly greater number of flowers for the $P$. dominula absent control treatment compared to both treatments where $P$. dominula was present (Tukey's post hoc, $P<0.05$ ). Many plants require a minimum number of leaves for floral initiation (Holdsworth, 1956), as the 
(a)
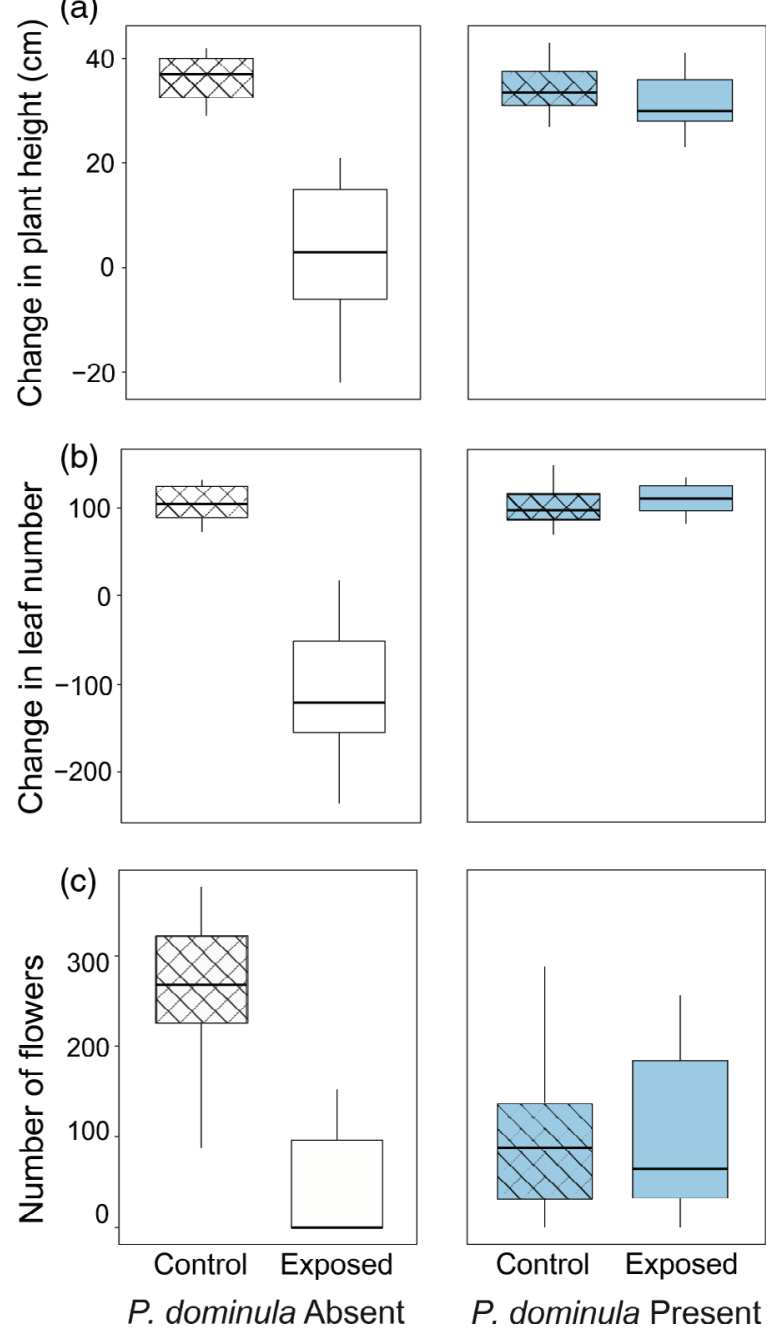

Fig. 7. Relative changes in milkweed plant (a) height, (b) leaf number, and (c) reproductive output in response to the presence or absence of the predatory wasp Polistes dominula. Exposed treatments allowed for monarch butterflies to lay eggs on milkweeds and for resulting caterpillars to feed on the host plant. Control treatments were plants covered by bug-exclusion nets to exclude monarch adults and caterpillars from having access to the milkweed plant, preventing herbivory. [Colour figure can be viewed at wileyonlinelibrary.com].

production of reproductive structures is energetically costly. The milkweed plants in the $P$. dominula present area had fewer leaves on average ( $113 \pm 5.2$ initial leaves) prior to the experiment than plants in the area without this wasp $(179 \pm 12.7$ initial leaves $)$. It is reasonable, therefore, to assume that the plants in the Nelson region had less flowers as they likely reached the minimum leaf number required to reproduce at a comparatively later stage.

\section{Discussion}

We found that the invasive wasp $P$. dominula can exert a predation pressure strong enough to initiate a trophic cascade. The removal of monarch caterpillars as a result of $P$. dominula predation significantly reduced herbivore load. This predation in turn yielded a significant increase in plant height and foliage for plants in the presence of $P$. dominula compared to plants in areas where this wasp was absent. These results were in accordance with predictions for plant growth, as monarch caterpillars consume the leaves and stems of the plant, causing substantial damage to their host. While the presence of $P$. dominula did not lead to a significant difference in flower production compared to exposed milkweeds in areas without this predator, the similarity in the number of flowers per plant compared to control plants in the Nelson region suggest that $P$. dominula is having a strong effect on reproductive output. Ideally, reproductive output would have been quantified as seed pod production rather than flowers for this study, but the nets used on control plants to exclude monarch caterpillars also excluded pollinators. However, our observations of self-sown, older milkweed plants in the region with $P$. dominula found these plants to be heavily loaded with seed pods. Therefore, it seems that the increased flowering level results in increased seed production.

Increases in $P$. dominula densities were found to significantly decrease the probability of caterpillar survival. Densities of $P$. dominula were highest in suburban areas, which was in accordance with findings of previous research that these wasps prefer to nest on anthropogenic structures (Roets et al., 2019). A higher rate of caterpillar predation in urban gardens was observed in a similar study investigating the predatory effects of $P$. dominula on monarch caterpillars in differing habitat types (Baker \& Potter, 2020). Coastal areas were found to contain comparatively fewer $P$. dominula nests than suburban areas, which appeared to be reflected in the lower mortality rates of caterpillars in these areas. No nests of either $P$. dominula or $P$. chinensis were found within forest habitats. This result was unsurprising as a negative correlation has been observed between Polistes and canopy cover (Schmack et al., 2020). Caterpillar loss in forest areas was not observed to be a result of predation and was likely due to fifth instar individuals leaving the plant to pupate. However, we cannot rule out the possibility of predation by another species, as predatory Vespula spp. have also established in New Zealand and been proven to significantly deplete Lepidopteran populations in forest habitats (Beggs \& Rees, 1999). The invasive paper wasp $P$. chinensis, which is documented as a predator of monarch caterpillars (Ward \& Ramón-Laca, 2013), accounted for a relatively small proportion of caterpillar deaths in suburban and coastal areas, perhaps due to its lower abundance compared to P. dominula.

Our study found $P$. dominula densities to significantly impact monarch caterpillar survival rates, yet surprisingly few wasps actually discovered, and killed, caterpillars. On average, only one wasp found, and successfully hunted prey on an experimental milkweed. This wasp then appeared to return to the plant repeatedly throughout the day, taking more caterpillars. The maximum number of wasps to successfully predate upon caterpillars on any individual milkweed plant during a 6-h trial was five. One explanation for this finding is the lack of recruitment behaviour in many social wasp species (Jeanne et al., 1995; Richter, 2000). Therefore, the discovery of caterpillars seemed 
to be an outcome of chance foraging success by an individual wasp.

Large caterpillars (late fourth to fifth instar) had a lower rate of mortality relative to small caterpillars (second to early fourth instar). This lower mortality is unsurprising based on observations in the field of large caterpillars thrashing about or dropping to the ground when touched by $P$. dominula, resulting in the wasp searching elsewhere. Similar observations were made in previous studies focused on the predation of monarch caterpillars by P. dominula (Rayor, 2004; Baker \& Potter, 2020). These findings suggest that if a caterpillar is able to survive through earlier instars, there is a size threshold where they are more likely to escape predation.

The results from the annual butterfly survey not only provide evidence that monarch butterfly populations have declined significantly since the establishment of $P$. dominula, but they show a decline in other Lepidopteran populations as well. One of the populations in decline was the common blue butterfly, Zizina labradus, which like the monarch butterfly, is a self-introduced species in New Zealand (Gibbs, 1980). Declines in populations of Pieris rapae (white butterfly) following the arrival of $P$. dominula is considered to be a beneficial outcome, as the caterpillars of this invasive pest eat the leaves of cabbage, broccoli, and other brassica vegetables. Paper wasps have been recommended as control agents against $P$. rapae, as predation by Polistes spp. has been found to significantly increase cabbage weight (Gould \& Jeanne, 1984).

The butterfly surveys coupled with results from our experiments give a compelling case that $P$. dominula exert a strong predation pressure on Lepidopteran species in New Zealand, which can indirectly influence lower trophic levels. As P. dominula is a generalist predator, it is possible that this wasp could be impacting not only the relationship between monarchs and their host, but also the host plants of other prey species. Invasive species have the capacity to reach high abundances within their invaded ranges. This phenomenon is often explained by factors such as enemy release (Torchin et al., 2003). High levels of abundance in addition to their exploitation of novel prey are what makes the impact of invasive predators so devastating (Beggs \& Rees, 1999; Piovia-Scott et al., 2017).

The upward trend in 2019 for both monarch and cabbage white butterflies suggests butterfly populations may be recovering. It is not uncommon for invasive insect populations to crash following an initial outbreak and population boom (Lester \& Gruber, 2016). The population decline of an invasive species is often attributed to causes such as parasites, disease outbreaks, competition, or resource availability (Strayer et al., 2017). The slight increase in butterfly abundance over the most recent summer could be an indicator that $P$. dominula is experiencing a population decline in that area. Even a small decline in wasp abundance may be sufficient to allow butterfly abundance to increase.

It has been observed that exotic species are capable of facilitating the invasion and spread of other exotic species (Relva et al., 2010). In addition to their positive, indirect effects through predation, $P$. dominula might also be having a direct, positive effect as a pollinator of milkweeds (Rafferty \& Ives, 2012). Several species of milkweeds have been introduced to New
Zealand, and in addition to G. physocarpus, the other two most common milkweed species are G. fruticosus and Asclepias curassavica. The milkweed Asclepias tuberosa, known in North America as the 'butterfly weed', is not imported to New Zealand for fear of it spreading and becoming an invasive weed (MPI, 2018). The abundance of milkweeds in New Zealand is currently controlled by the intense herbivory of monarch caterpillars (Wise, 1980). Herbivore removal can potentially cause harm if there are no other regulating factors in place to control exotic plant species (Zavaleta et al., 2001). Released from this regulation by the indirect effect of $P$. dominula predation, $G$. physocarpus and other milkweed species could become so abundant as to be perceived as invasive weeds. More definitive research would need to be conducted to test this, but initial observations suggest that one invasive pest species may have created another.

\section{Acknowledgements}

For giving us permission to collect the data required to conduct this study, we would like to thank the residents of Nelson and Masterton, particularly Alan Pattie, David Bloomfield, Julia and Brian Flintoff, John and Nona Pinel, Andrea and Craig Thomson, Mike and Nick McGruddy, and Carol Parton. Funding was provided by Victoria University of Wellington. The authors have no conflicts of interest to disclose.

\section{Contributions of Authors}

R.A.M. designed the experiments, analysed the data, and wrote the draft manuscript, R.A.M., M.W.F.H., C.J.I.W., and T.B.S. collected the data, J.H. aided in interpreting the results and advised on statistical analyses plus edited the manuscript, M.H-W. compiled the data for the annual butterfly survey, P.J.L. and R.J.T. assisted with conceptualisation and supervised the work. All authors read and approved the final manuscript.

\section{Data availability statement}

The data that support the findings of this study are openly available in "figshare" at http://doi.org/10.6084/m9. figshare. 12926624

\section{Supporting Information}

Additional supporting information may be found online in the Supporting Information section at the end of the article.

Table S1. Table presenting the average butterfly abundance for the summer that year, alongside climatic variables.

Fig. S1. Data from an annual survey in Nelson showing mean butterfly abundance and total rainfall for three species.

Fig. S2. Data from an annual survey in Nelson showing mean butterfly abundance and average air temperature for three species. 
Table S2. Table presenting the results of an ANOva investigating the difference in total rainfall or average air temperatures.

Table S3. Number of wasps and nests for $P$. dominula and $P$. chinensis at each site during the experiment investigating the predation of monarch caterpillars.

\section{References}

Baker, A.M. \& Potter, D.A. (2020) Invasive paper wasp turns urban pollinator gardens into ecological traps for monarch butterfly larvae. Scientific Reports, 10, 1-7.

Beggs, J.R. \& Rees, J.S. (1999) Restructuring of Lepidoptera communities by introduced Vespula wasps in a New Zealand beech forest. Oecologia, 119, 565-571.

Beggs, J.R., Brockerhoff, E.G., Corley, J.C., Kenis, M., Masciocchi, M., Muller, F. et al. (2011) Ecological effects and management of invasive alien Vespidae. BioControl, 56, 505-526.

Benade, P.C., Veldtman, R., Samways, M.J. \& Roets, F. (2014) Rapid range expansion of the invasive wasp Polistes dominula (Hymenoptera: Vespidae: Polistinae) and first record of parasitoids on this species and the native Polistes marginalis in the Western Cape province of South Africa. African Entomology, 22, 220-225.

Beschta, R.L. \& Ripple, W.J. (2009) Large predators and trophic cascades in terrestrial ecosystems of the western United States. Biological Conservation, 142, 2401-2414.

Borer, E.T., Halpern, B.S. \& Seabloom, E.W. (2006) Asymmetry in community regulation: effects of predators and productivity. Ecology, 87, 2813-2820.

Britten, G.L., Dowd, M., Minto, C., Ferretti, F., Boero, F. \& Lotze, H.K. (2014) Predator decline leads to decreased stability in a coastal fish community. Ecology Letters, 17, 1518-1525.

Brockerhoff, E., Barratt, B.I.P., Beggs, J., Fagan, L., Kay, M., Phillips, C. et al. (2010) Impacts of exotic invertebrates on New Zealand's indigenous species and ecosystems. New Zealand Journal of Ecology, 34, 158-174.

Cervo, R., Zacchi, F. \& Turillazzi, S. (2000) Polistes dominulus (Hymenoptera, Vespidae) invading North America: some hypotheses for its rapid spread. Insectes Sociaux, 47, 155-157.

Clapperton, B., Tilley, J. \& Pierce, R. (1996) Distribution and abundance of the Asian paper wasp Polistes chinensis antennalis Perez and the Australian paper wasp P. humilis (Fab.)(Hymenoptera: Vespidae) in New Zealand. New Zealand Journal of Zoology, 23, 19-25.

Dew, H.E. \& Michener, C.D. (1978) Foraging flights of two species of Polistes wasps (Hymenoptera: Vespidae). Journal of the Kansas Entomological Society, 51, 380-385.

Gibbs, G.W. (1980) New Zealand Butterflies: Identification and Natural History. Collins, Auckland, New Zealand.

Gould, W.P. \& Jeanne, R. (1984) Polistes wasps (Hymenoptera: Vespidae) as control agents for lepidopterous cabbage pests. Environmental Entomology, 13, 150-156.

Gurevitch, J. \& Padilla, D.K. (2004) Are invasive species a major cause of extinctions? Trends in Ecology \& Evolution, 19, 470-474.

Halaj, J. \& Wise, D.H. (2001) Terrestrial trophic cascades: How much do they trickle? The American Naturalist, 157, 262-281.

Holdsworth, M. (1956) The concept of minimum leaf number. Journal of Experimental Botany, 7, 395-409.

Holway, D.A., Lach, L., Suarez, A.V., Tsutsui, N.D. \& Case, T.J. (2002) The causes and consequences of ant invasions. Annual Review of Ecology and Systematics, 33, 181-233.

Jager, K.J., Van Dijk, P.C., Zoccali, C. \& Dekker, F.W. (2008) The analysis of survival data: the Kaplan-Meier method. Kidney International, 74, 560-565.
Jeanne, R.L., Hunt, J.H. \& Keeping, M.G. (1995) Foraging in social wasps: Agelaia lacks recruitment to food (Hymenoptera: Vespidae). Journal of the Kansas Entomological Society, 68, 279-289.

Lester, P.J. \& Beggs, J.R. (2019) Invasion success and management strategies for social Vespula wasps. Annual Review of Entomology, 64, 51-71.

Lester, P.J. \& Gruber, M.A. (2016) Booms, busts and population collapses in invasive ants. Biological Invasions, 18, 3091-3101.

Liebert, A.E., Gamboa, G.J., Stamp, N.E., Curtis, T.R., Monnet, K.M., Turillazzi, S. et al. (2006) Genetics, behavior and ecology of a paper wasp invasion: Polistes dominulus in North America. Annales Zoologici Fennici, 43, 595-624.

Liere, H., Kim, T.N., Werling, B.P., Meehan, T.D., Landis, D.A. \& Gratton, C. (2015) Trophic cascades in agricultural landscapes: indirect effects of landscape composition on crop yield. Ecological Applications, 25, 652-661.

Moon, D.C. \& Silva, D. (2013) Environmental heterogeneity mediates a cross-ecosystem trophic cascade. Ecological Entomology, 38, 23-30.

MPI (2016) European Paper Wasp. Ministry for Primary Industries, New Zealand [WWW document]. URL https://www.pmanz.nz/ uploads/5/3/1/0/53106237/european_paper_wasp_fs_sept2016_web .pdf [accessed on 5 August 2020].

MPI (2018) Schedule of Regulated (Quarantine) Weed Seeds. Ministry for Primary Industries, New Zealand [WWW document]. URL https:// www.biosecurity.govt.nz/dmsdocument/7111/direct [accessed on 16 October 2020].

NIWA (2016) Regional Climatologies. National Institute of Water and Atmospheric Research, New Zealand [WWW document]. URL https://niwa.co.nz/our-science/climate/publications/regionalclimatologies [accessed on 25 November 2019].

O'Dowd, D.J., Green, P.T. \& Lake, P.S. (2003) Invasional 'meltdown' on an oceanic island. Ecology Letters, 6, 812-817.

Piovia-Scott, J., Yang, L.H. \& Wright, A.N. (2017) Temporal variation in trophic cascades. Annual Review of Ecology, Evolution, and Systematics, 48, 281-300.

Potter-Craven, J., Kirkpatrick, J.B., McQuillan, P.B. \& Bell, P. (2018) The effects of introduced vespid wasps (Vespula germanica and $V$-vulgaris) on threatened native butterfly (Oreixenica ptunarra) populations in Tasmania. Journal of Insect Conservation, 22, 521-532.

R Development Core Team (2020) R: A Language and Environment for Statistical Computing. R Foundation for Statistical Computing, Vienna, Austria [WWW document]. URL https://www.R-project.org.

Rafferty, N.E. \& Ives, A.R. (2012) Pollinator effectiveness varies with experimental shifts in flowering time. Ecology, 93, 803-814.

Rayor, L.S. (2004) Effects of Monarch Larval Host Plant Chemistry and Body Size on Polistes Wasp Predation. Cornell University Press, Ithaca, New York.

Relva, M.A., Nunez, M.A. \& Simberloff, D. (2010) Introduced deer reduce native plant cover and facilitate invasion of non-native tree species: evidence for invasional meltdown. Biological Invasions, 12, 303-311.

Richter, M.R. (2000) Social wasp (Hymenoptera: Vespidae) foraging behavior. Annual Review of Entomology, 45, 121-150.

Roets, F., Benade, P.C., Samways, M.J. \& Veldtman, R. (2019) Better colony performance, not natural enemy release, explains numerical dominance of the exotic Polistes dominula wasp over a native congener in South Africa. Biological Invasions, 21, 925-933.

Rosumek, F., Silveira, F., Neves, S., F., U, Barbosa, N., Diniz, L. et al. (2009) Ants on plants: a meta-analysis of the role of ants as plant biotic defenses. Oecologia, 160, 537-549.

Salo, P., Korpimäki, E., Banks, P.B., Nordström, M. \& Dickman, C.R. (2007) Alien predators are more dangerous than native predators to prey populations. Proceedings of the Royal Society B: Biological Sciences, 274, 1237-1243. 
Schmack, J., Schleuning, M., Ward, D. \& Beggs, J. (2020) Biogeography and anthropogenic impact shape the success of invasive wasps on New Zealand's offshore islands. Diversity and Distributions, 26, 441-452.

Shears, N.T. \& Babcock, R.C. (2002) Marine reserves demonstrate top-down control of community structure on temperate reefs. Oecologia, 132, 131-142.

Strayer, D.L., D'Antonio, C.M., Essl, F., Fowler, M.S., Geist, J., Hilt, S. et al. (2017) Boom-bust dynamics in biological invasions: towards an improved application of the concept. Ecology Letters, 20, $1337-1350$.

Terborgh, J., Lopez, L., Nunez, P., Rao, M., Shahabuddin, G., Orihuela, G. et al. (2001) Ecological meltdown in predator-free forest fragments. Science, 294, 1923-1926.

Tibbetts, E.A. \& Dale, J. (2004) A socially enforced signal of quality in a paper wasp. Nature, 432, 218-222.

Tibbetts, E.A. \& Lindsay, R. (2008) Visual signals of status and rival assessment in Polistes dominulus paper wasps. Biology Letters, $\mathbf{4}$, 237-239.

Toft, R.J. \& Rees, J.S. (1998) Reducing predation of orb-web spiders by controlling common wasps (Vespula vulgaris) in a New Zealand beech forest. Ecological Entomology, 23, 90-95.
Torchin, M.E., Lafferty, K.D., Dobson, A.P., Mckenzie, V.J. \& Kuris, A.M. (2003) Introduced species and their missing parasites. Nature, 421, 628.

Ward, D.F. \& Ramón-Laca, A. (2013) Molecular identification of the prey range of the invasive Asian paper wasp. Ecology and Evolution, 3, 4408-4414.

Wise, K. (1980) Monarch butterfly dispersal in New Zealand. Auckland War Memorial Museum, 17, 157-173.

Worm, B. \& Myers, R.A. (2003) Meta-analysis of cod-shrimp interactions reveals top-down control in oceanic food webs. Ecology, 84, $162-173$.

Zalucki, M.P. \& Clarke, A.R. (2004) Monarchs across the Pacific: the Columbus hypothesis revisited. Biological Journal of the Linnean Society, 82, 111-121.

Zavaleta, E.S., Hobbs, R.J. \& Mooney, H.A. (2001) Viewing invasive species removal in a whole-ecosystem context. Trends in Ecology and Evolution, 16, 454-459.

Accepted 23 November 2020

First published online 9 December 2020

Associate Editor: Walter Araújo 